\title{
The Interaction of PI3K Inhibition with Homologous Recombination Repair in Triple Negative Breast Cancer Cells
}

\author{
Gamze Guney Eskiler \\ Department of Medical Biology, Faculty of Medicine, Sakarya University, Sakarya, Turkey. \\ Received, August 6, 2019; Revised, September 20, 2019; Accepted, October 31, 2019; Published, November 6, 2019.
}

\begin{abstract}
Purpose: Aberrant activation of the phosphatidylinositol 3'-kinase (PI3K)-Akt signaling pathway is observed in many types of human cancer including triple negative breast cancer (TNBC). Additionally, dysregulation in the homologous recombination (HR)-dependent DNA-repair is associated with TNBC phenotype due to BRCA1/2 mutations or HR deficiency. Therefore, the hypothesis of this study was to evaluate the association of PI3K inhibition with HR pathway in TNBC in terms of BRCA1 mutation status. Methods: To examine the potential therapeutic effect of LY294002, an inhibitor of PI3K, on TNBC cell lines with known BRCA1 status, WST-1, annexin V, cell cycle analysis and AO/EB staining were performed. Additionally, RT-PCR and immunofluorescence analysis was used to explore the interaction between the inhibition of PI3K and HR functionality. Results: The findings showed that LY294002 could significantly inhibited the proliferation of TNBC cells. Furthermore, the suppression of PI3K resulted in HR impairment by $B R C A 1$ and $R A D 51$ downregulation and apoptotic cell death by the induction of DNA damage and $B A X$ overexpression. Therefore, LY294002 was more effective in BRCA1-deficient TNBC cells. Conclusions: Consequently, targeted therapies based on the interaction of PI3K inhibition with BRCA1 mutations or HR deficiency in TNBC may be a promising strategy for the treatment of patients with TNBC.
\end{abstract}

\section{INTRODUCTION}

Triple-negative breast cancer (TNBC) is a sub-type of breast cancer with a worst prognosis among all subtypes of breast cancer. Treatment of TNBC is based on the using of different chemotherapeutic agents for neoadjuvant or adjuvant therapy. However, there is no effective and molecularly targeted treatment options for TNBC due to heterogeneity of disease (1-4). Therefore, there is urgently needed to identify the potential molecular target for TNBC therapy.

Mutations in the $B R C A 1 / 2$ genes, play a crucial role in the homologous recombination (HR) mechanism to repair of double-strand DNA break (dsDNA), are strongly associated with TNBC. Several studies have identified that the prevalence of the BRCA1/2 mutation in unselected TNBC patients for age and family history is between 9.4 and $18.2 \%$ in the literature (4-7). Additionally, there is increasing evidence that further genes involved in HR pathway are associated with the TNBC phenotype (8-10). Thus, therapeutic approaches targeting $B R C A$ mutation and/or HR deficiency status are more effective for developing of successful treatment strategies for TNBC patients.

The phosphatidylinositol 3-kinase (PI3K)/ AKT-pathway is a crucial intracellular signaling pathway in cell growth, proliferation and metabolism and over-activation of the pathway promotes cancer cell proliferation, invasion and

metastasis (11,12). TNBC exhibits aberrant activation of PI3K pathway through different mechanism including loss of PTEN, overexpression of EGFR and mutations in PIK3CA gene. Additionally, an interaction between PI3K and HR pathway is an essential role in DNA repair through replication fork stabilization under physiological conditions. Therefore, the PI3K/AKT pathway represents therapeutic potential in TNBC patients (13-15).

In this context, we investigated for the first time that the interaction of PI3K inhibition by the PI3K inhibitor, LY294002 with HR pathway in TNBC, in vitro. For this purpose, the therapeutic potential of LY294002 in two of the TNBC cell lines (HCC1937 and MDA-MB-231) in terms of $B R C A 1$ mutation status was assessed in the current study. Consequently, blockage of the PI3K pathway can lead to HR impairment by downregulating BRCA1 and RAD51 and increase DNA damage and subsequently apoptotic cell death.

Corresponding Author: Gamze Güney Eskiler: E-Mail: gamzeguney@sakarya.edu.tr, Mail:Department of Medical Biology, Medical Faculty, Sakarya University, Korucuk Campus, Sakarya, Turkey. 


\section{METHODS}

\section{Cell culture}

HCC1937 (BRCA1 mutant), MDA-MB-231 (BRCA1 wild-type) TNBC cell lines and MCF$10 \mathrm{~A}$ human breast epithelial cell line were purchased from the American Type Culture Collection (ATCC, Rockville, MD, USA). HCC1937 cells were grown in RPMI-1640 media (Gibco, Thermo Fisher Scientific, Waltham, MA, USA) whereas MDA-MB-231 cells were cultured in Dulbecco's modified Eagle's medium (DMEM, Gibco, Thermo Fisher Scientific, Waltham, MA, USA) supplemented with $10 \%$ fetal bovine serum (FBS) (Gibco, Thermo Fisher Scientific, Waltham, MA, USA) and $1 \%$ penicillin-streptomycin (Gibco, Thermo Fisher Scientific, Waltham, MA, USA). For MCF-10A cells, Dulbecco's Modified Eagle's Medium/Nutrient Mixture F-12 (DMEM F-12, Gibco, Thermo Fisher Scientific, Waltham, MA, USA) supplemented with $100 \mathrm{mg} / \mathrm{mL}$ EGF (Biovision, San Francisco, CA, USA), $1 \mathrm{mg} / \mathrm{mL}$ hydrocortisone (Sigma-Aldrich, St Louis, MO, USA), $10 \mathrm{mg} / \mathrm{mL}$ insulin (Sigma-Aldrich, St Louis, MO, USA), $10 \%$ FBS, and $1 \%$ penicillin and streptomycin was used. Cells were cultured at $37^{\circ} \mathrm{C}$ in humidified air with $5 \% \mathrm{CO}_{2}$.

\section{WST-1 Analysis}

LY294002 was purchased from Biovision (San Francisco, CA, USA) and stock solution of LY294002 was prepared by DMSO and stored at $20^{\circ} \mathrm{C}$. In briefly, cells were seeded in 96-well plates. After 24 and 48 hours of incubation with LY294002 (0-20 $\mu \mathrm{M})$, WST-1 dye (Biovision, San Francisco, CA, USA) was added into each well and incubated with $30 \mathrm{~min}$ in the dark. Then, cell viability was determined by microplate reader at $450 \mathrm{~nm}$ (Allsheng, China).

\section{Apoptotic Analysis}

For Annexin V analysis, cells were trypsinized and washed with PBS after $48 \mathrm{~h}$ of incubation with different concentrations of LY294002. Then, cells were stained with Muse ${ }^{\mathrm{TM}}$ Annexin V \& Dead Cell Assay kit (Millipore, Germany) and incubated for 30 minutes in the dark condition. For cell cycle analysis, cells were fixed in ice-cold $70 \%$ ethanol in PBS and kept at $-20^{\circ} \mathrm{C}$ for at least three hours. Afterwards, cells were centrifuged and stained with Muse ${ }^{\mathrm{TM}}$ Cell Cycle Kit (Merck Millipore, Germany) for 30 minutes in the dark condition. Finally, each experiment was analyzed at Muse ${ }^{\mathrm{TM}}$ Cell Analyzer (Merck Millipore, Germany) $(n=3)$.
Acridine Orange (AO) and Ethidium Bromide (EB) Staining

Following different concentration of LY294002 exposure, cells were washed with PBS and fixed with $4 \%$ paraformaldehyde. Afterwards, cells were stained with $\mathrm{AO} / \mathrm{EB}$ for 30 minutes. After washing twice with PBS, all images were recorded by a EVOS FL Cell Imaging System (Thermo Fisher Scientific, Waltham, MA, USA).

\section{Gene expression}

High Capacity cDNA Reverse Transcription Kit (Thermo Fisher Scientific, Waltham, MA, USA was used for cDNA synthesis after total RNA isolation with an E.Z.N.A. Total RNA Kit (Omega Bio-Tek, Norcross, GA). RT-PCR was performed using the Step One Plus ${ }^{\mathrm{TM}}$ Real-Time PCR (Applied Biosystems, Foster City, CA) to detect changes in the H2AFX, BRCA1, RAD51, BCL-2 and $B A X$ gene expression levels. ACTB was used as an internal normalization control. Differentially expressed genes were analyzed by Qiagen software tool.

\section{Immunofluorescence Analysis}

Immunofluorescence analysis of $\gamma \mathrm{H} 2 \mathrm{AX}$, BRCA1 and RAD51 was conducted on HCC1937 and MDA-MB-231 cells after $48 \mathrm{~h}$ of exposure to LY294002. After incubation, cells were fixed with $4 \%$ paraformaldehyde, permeabilized and blocked with $0.1 \%$ Triton X-100 and 5\% goat serum in $1 \times$ PBS medium for 1 hour. Subsequently, cells were incubated with anti-mouse $\gamma \mathrm{H} 2 \mathrm{AX}, \mathrm{BRCA} 1$ and RAD51 primer antibodies at a dilution of 1:250, $1: 200$ and 1:10, respectively for two hours. Then, anti-mouse Alexa Fluor 488 goat IgG was diluted 1:1000 and incubated for 60 minutes. Finally, DAPI was used for visualization of nuclei. Images were acquired using an EVOS FL Cell Imaging System (Thermo Fisher Scientific, Waltham, MA, USA).

\section{STATISTICAL ANALYSIS}

One-way ANOVA with Post-hoc Tukey test and two-way repeated measures ANOVA were performed by using SPSS 22.0 (SPSS Inc., Chicago, IL, USA) for multiple comparison. All experiments were repeated at least 3 times and the obtained data presented as the mean \pm standard deviation. $\mathrm{P}<0.05$ was considered significant. 


\section{RESULTS}

Cytotoxic effect of LY294002, PI3K inhibitor on TNBC cell lines

To determine the effects of LY294002 on cell proliferation, we carried out WST-1 assay. As shown in Figure 1, we determined that LY294002 significantly inhibited the proliferation of TNBC cells $(\mathrm{p}<0.05)$. Exposure to $10 \mu \mathrm{M}$ of LY294002 led to $52.9 \pm 0.3 \%$ and $22.4 \pm 4.4 \%$ cell death in HCC1937 and MDA-MB-231 cells, respectively for $48 \mathrm{~h}$. Additionally, a considerable inhibition $(55.5 \pm 1.7 \%$ and $41.8 \pm 2.6 \%)$ was observed at 20 $\mu \mathrm{M}$ for $48 \mathrm{~h}$ in TNBC cells (HCC1937 and MDAMB-231 cells, respectively, $\mathrm{p}<0.01)$. Therefore, HCC1937 cells were more sensitive to LY294002 compared with MDA-MB-231 cells. On the other hand, treatment with 10 and $20 \mu \mathrm{M}$ of LY294002 resulted in a decrease $(75.6 \pm 2.7 \%$ and $65.6 \pm$ $5.3 \%$, respectively) the viability of MCF-10A cells for $48 \mathrm{~h}$.

Furthermore, a two-way repeated measures ANOVA analysis was performed to evaluate the differences between the anti-proliferative effect of LY294002 and cell type compared to control cells. As shown in Table 1, all measured values of the different concentration of LY294002 were statistically significant in each cell type (F: 262.240; $<<0.01$ and F: $244.001 ; p<0.01$ for 24 and 48 hours, respectively). The interaction between the different concentrations LY294002 and cell type was statistically significant (F:25.377; p:0.001 and F:19.533; p:0.009 for 24 and 48 hours, respectively). Moreover, there was a statistical significance in terms of cell type (F: 140.100; $\mathrm{p}<0.01$ and F: $402.233 ; \mathrm{p}<0.01$ for 24 and 48 hours, respectively). Therefore, the results of WST-1 analysis were statistically supported by two-way repeated measures ANOVA.

\section{Impact of LY294002 on apoptotic cell death}

Annexin V analysis was performed to assess the apoptotic effects of LY294002 on TNBC cell lines. The findings demonstrated that a remarkable increase in the percentage of apoptotic cells after $48 \mathrm{~h}$ of incubation with LY294002 in TNBC cells (Figure 2, $\mathrm{p}<0.01$ ). Total apoptotic cells increased from $4.4 \pm 0.2 \%$ and $1.7 \pm 0.1 \%$ to $62.8 \pm 1.0 \%$ and $42.3 \pm 1.9 \%$ in HCC1937 and MDA-MB-231 cells, respectively at $20 \mu \mathrm{M}$ of LY294002. Furthermore, LY294002 treatment resulted in a dose-dependent increase in early and late apoptosis in TNBC cells compared to control group. However, LY294002 treatment caused a marked increase in the percentage of total apoptotic MCF-10A cells (31.3 $\pm 1.7 \%$ at $20 \mu \mathrm{M}, \mathrm{p}<0.01)$. Thus, the obtained findings were consistent with WST-1 analysis and LY294002 especially induced early apoptotic cell death in TNBC cells.

\section{A}

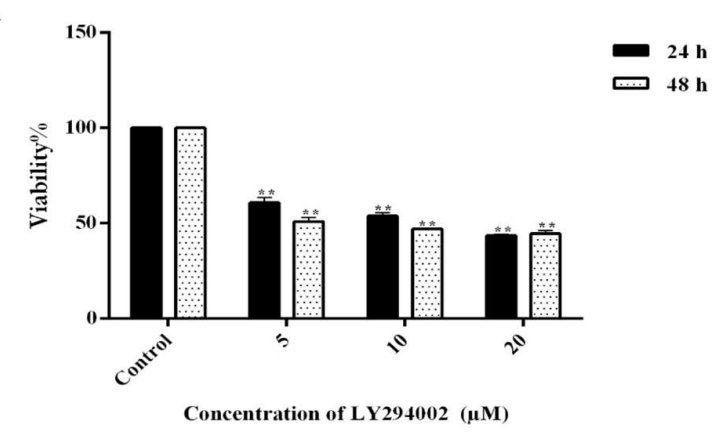

B

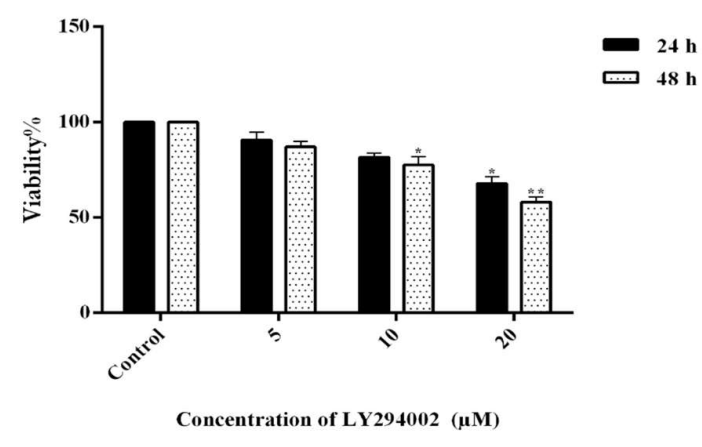

C

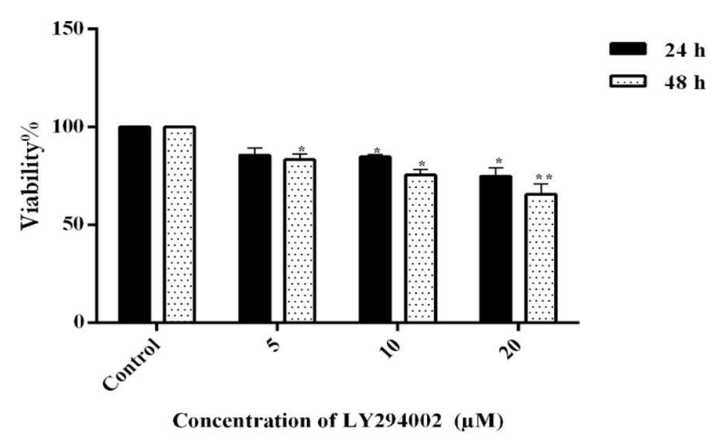

Figure 1. WST-1 results of (A) HCC1937, (B) MDAMB-231 and (C) MCF-10A cells after treatment with 5, 10 and $20 \mu \mathrm{M}$ concentrations of LY294002 for 24 and 48 hours $\left(\mathrm{p}<0.05^{*}, \mathrm{p}<0.01 * *\right)$.

To further confirm LY294002-induced cell death, the differences in cell cycle phase distribution were assessed (Figure 3). Incubation of TNBC and MCF-10A cells with LY294002 led to a remarkable increase of the $\mathrm{G} 0 / \mathrm{G} 1$ peak $(\mathrm{p}<0.01)$. Furthermore, a dose dependent increase in G0/G1 phase was detected after exposure to LY294002 in TNBC cells irrespective of $B R C A 1$ mutation status. However, the percentage of G0/G1 phase in HCC1937 cells was remarkably higher than that in MDA-MB-231 cells. 

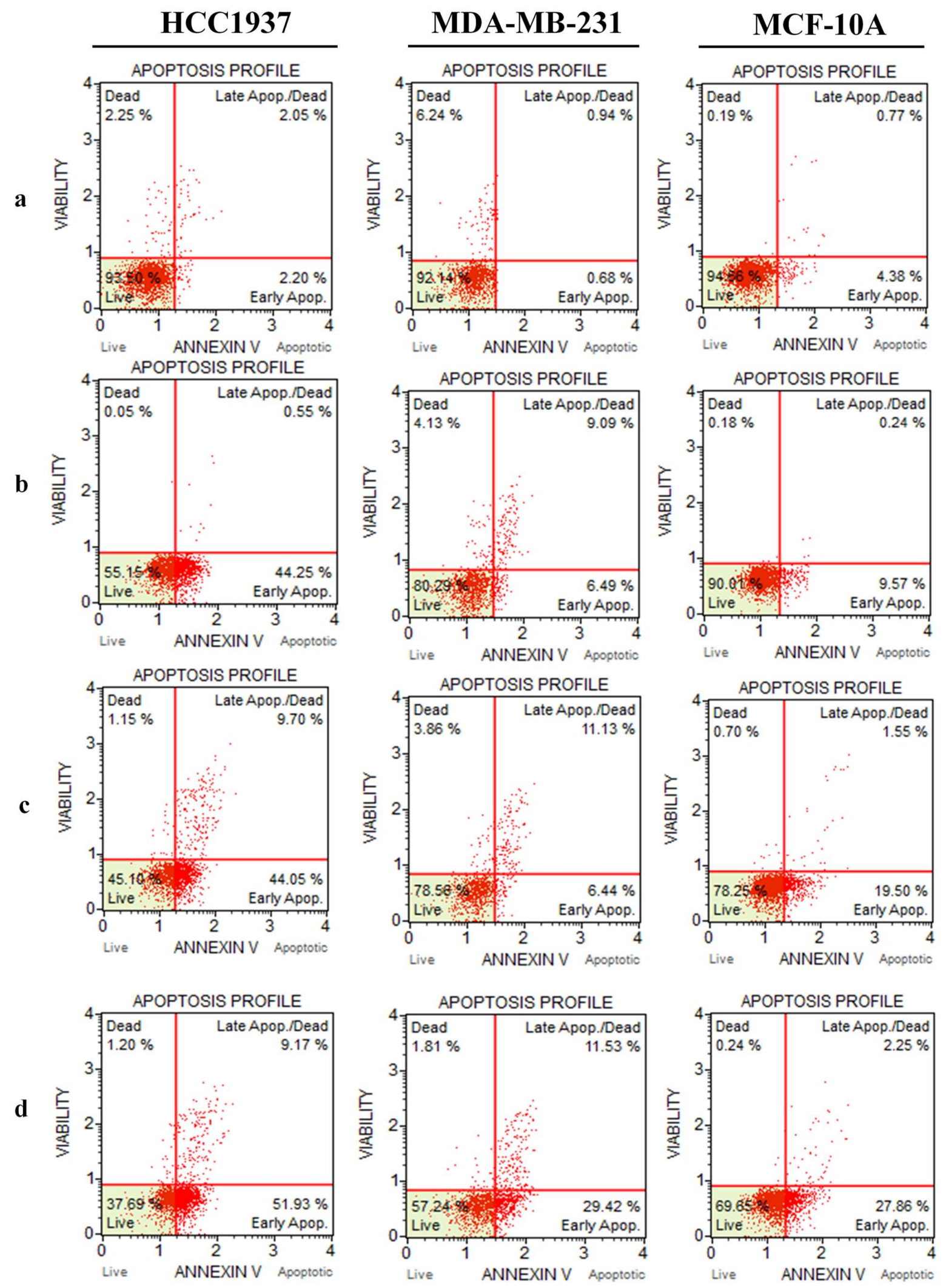

Figure 2. Induction of apoptosis by LY294002 treatment in TNBC and MCF-10A cells. (a) Control, (b) $5 \mu \mathrm{M}$, (c) 10 $\mu \mathrm{M}$ and (d) $20 \mu \mathrm{M}$ of LY294002. 

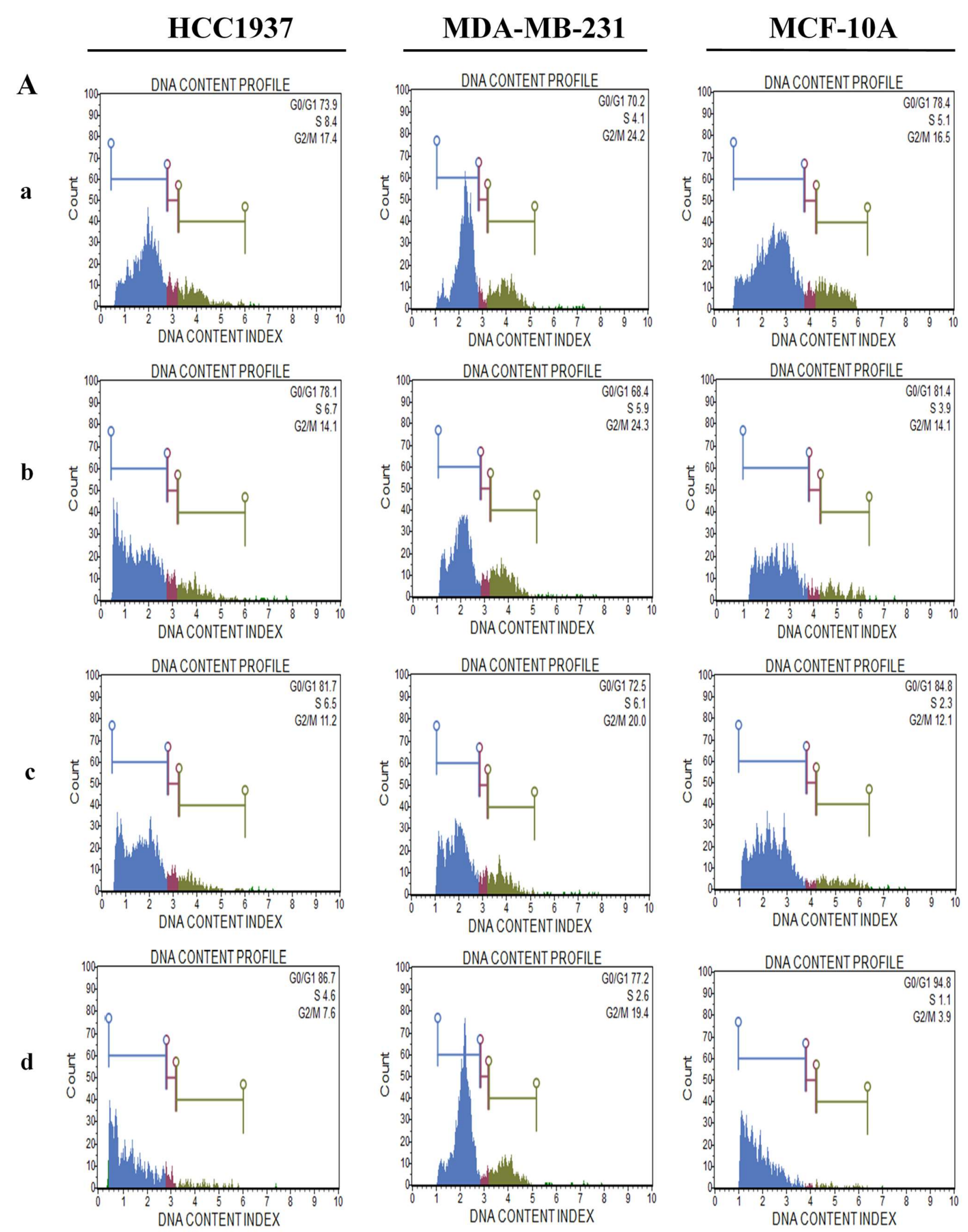

Figure 3. 
Figure 3.... Continued

B
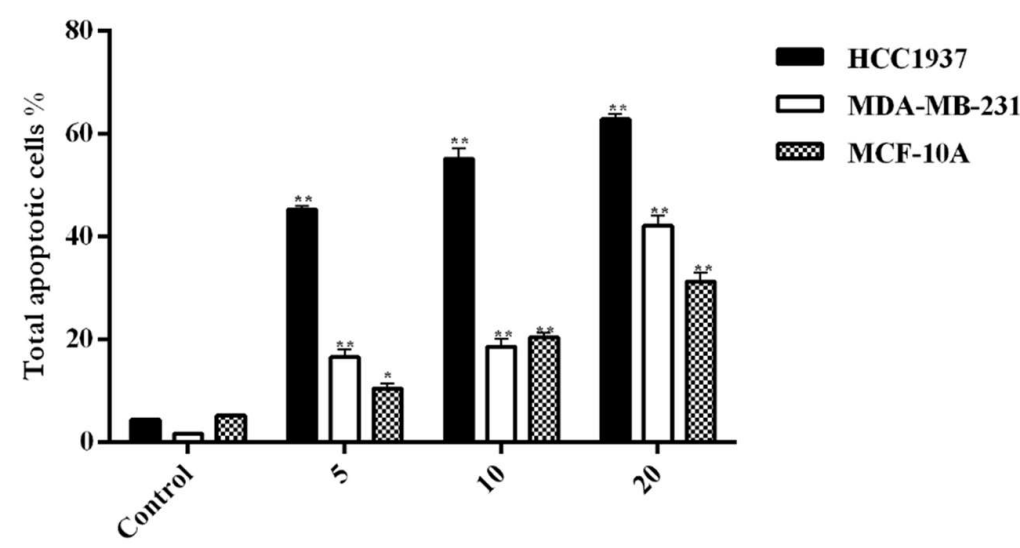

Concentration of LY294002 $(\mu \mathrm{M})$
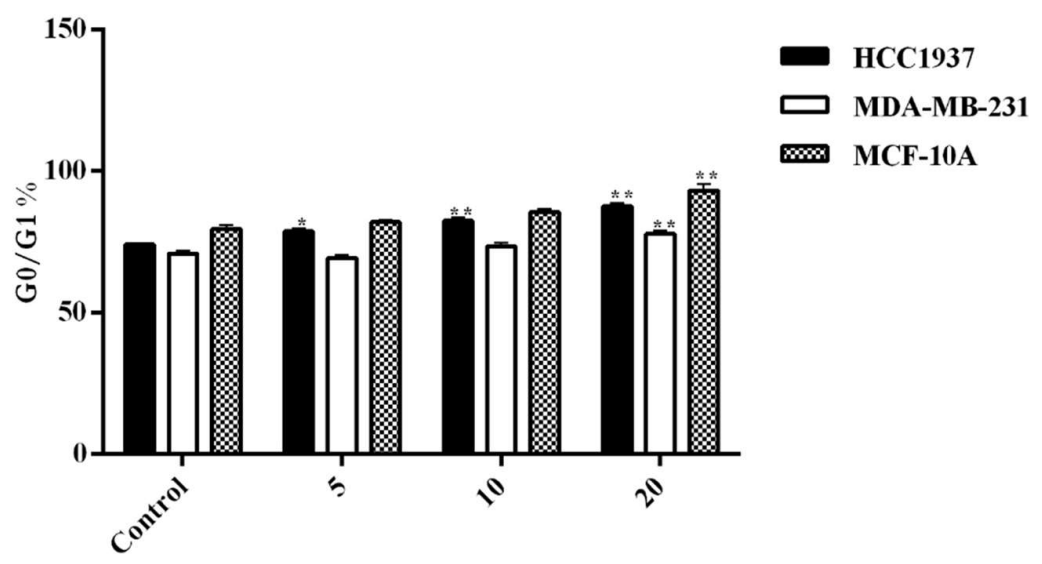

Concentration of LY294002 $(\mu \mathrm{M})$

Figure 3. (A) Inhibition of PI3K by LY294002 caused cell cycle arrest at G0/G1 phase in TNBC and control cells. These cells were treated with (a) Control, (b) $5 \mu \mathrm{M}$, (c) $10 \mu \mathrm{M}$ and (d) $20 \mu \mathrm{M}$ of LY294002. (B) Statistical comparison of LY294002-induced total apoptotic cells and G0/G1 phase cell cycle arrest in HCC1937, MDA-MB-231and MCF10 A cells $\left(\mathrm{p}<0.05^{*}, \mathrm{p}<0.01^{* *}\right)$.

\section{Cell morphological changes following incubation with LY294002}

LY294002 treated cells were stained with AO/EB to observe and validate LY294002-induced apoptotic cell death (Figure 4). In general, TNBC and MCF-10A cells exhibited fragmented green nucleus as sign of early apoptotic cells following incubation with LY294002 compared to each control group. Additionally, some yellow/green dots of condensed nuclei as well as intracytoplasmic vacuoles were observed in MDA-MB-231 cells at $20 \mu \mathrm{M}$ of LY294002 due to late apoptosis. On the other hand, LY294002 induced cell shrinkage and rounding morphology in MCF-10A cells at the highest concentration.

\section{Effect of LY294002 on HR-related genes expression level}

The expression levels of $H 2 A F X, B R C A 1$ and $R A D 51$ in TNBC and control cell lines were also identified by RT-PCR and the findings were summarized in Figure 5A. LY294002 significantly down-regulated BRCA1 and RAD51 expression levels whereas the overexpression of $H 2 A F X$ was determined in TNBC and control cell lines. However, the relative $B R C A 1$ and RAD51 mRNA expression levels were significantly higher in BRCA1 proficient MDA-MB-231 cells than $B R C A 1$ deficient HCC1937 cells. On the other hand, $H 2 A F X$ expression was significantly increased in HCC1937 cells compared with MDA- 
MB-231 cells $(\mathrm{p}<0.01)$. Furthermore, H2AFX mRNA level was expressed at higher levels in MCF-10A cells $(\mathrm{p}<0.01)$.

Furthermore, the expression level of two genes $(B C L-2$ and $B A X)$ associated with cell death were also determined to validate LY294002induced apoptotic cell death in Figure 5B.
LY294002 dose-dependently increased $B A X$ expression and decreased $B C L-2$ expression in TNBC cells $(\mathrm{p}<0.01)$. Therefore, inhibition of PI3K by LY294002 resulted in DNA damage, suppression of HR and caused apoptotic cell death in TNBC cells. a
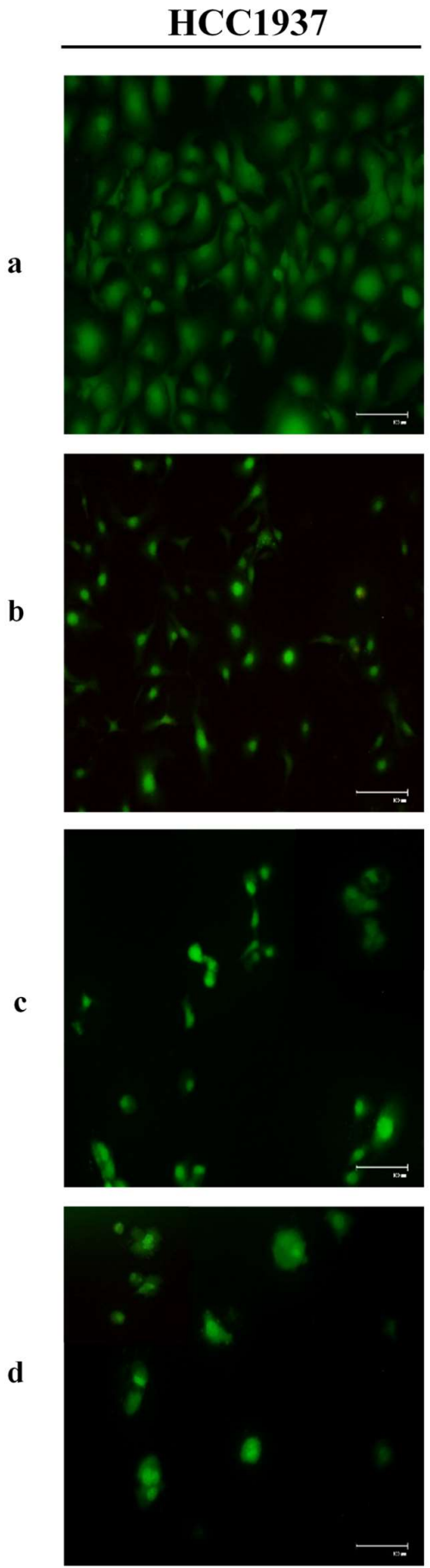
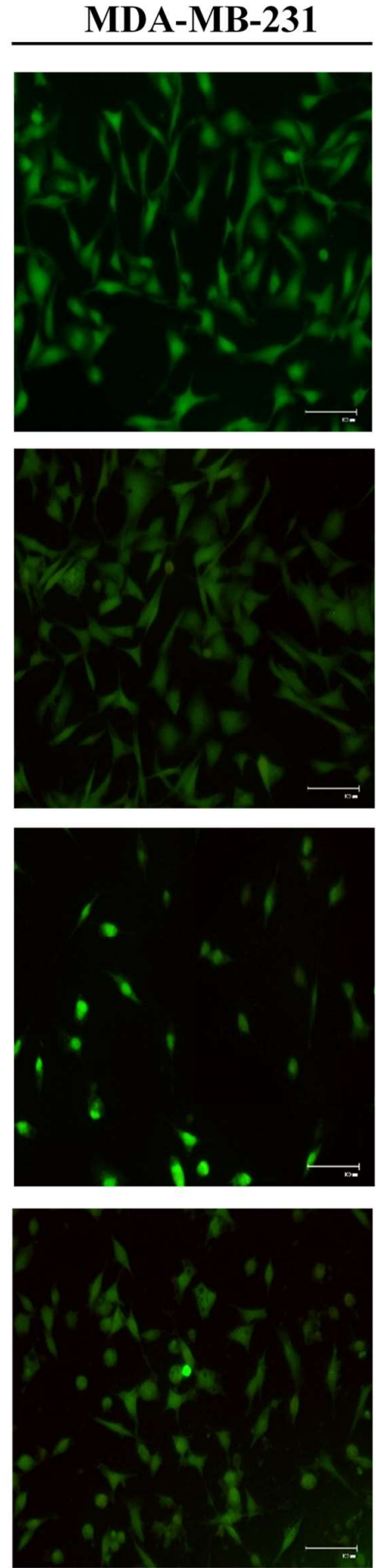

MCF-10A
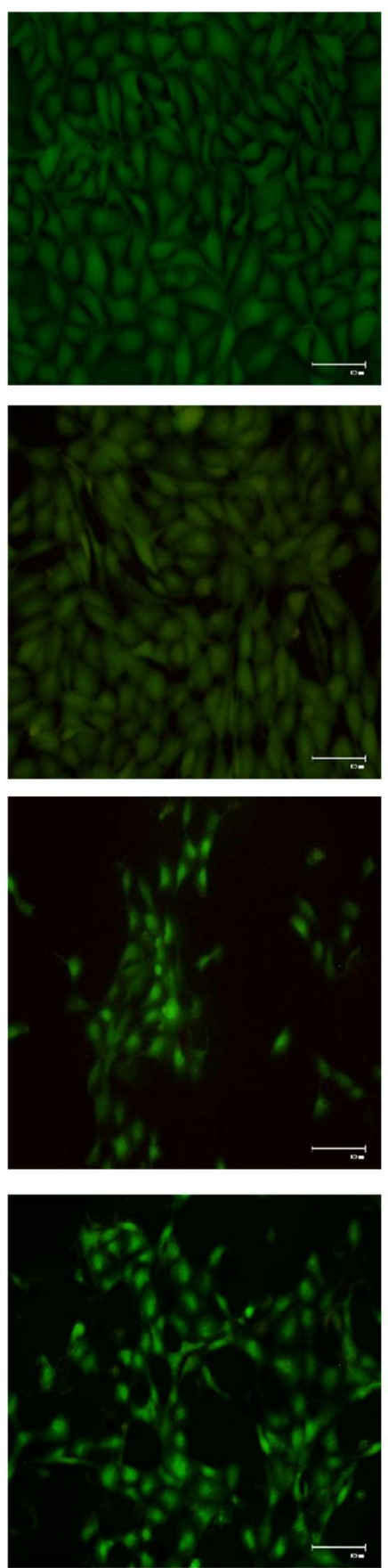

Figure 4. Results of AO/EB staining of cells exposed to different concentrations of LY294002 [(a) Control, (b) $5 \mu$ M, (c) $10 \mu \mathrm{M}$ and (d) $20 \mu \mathrm{M}$ ] to observe morphological changes in TNBC and MCF-10A cells. 
Evaluation of HR-related protein expression by immunofluorescence

The foci formation of $\gamma \mathrm{H} 2 \mathrm{AX}$ and the localization of BRCA1 and RAD51 in response to $20 \mu \mathrm{M}$ of LY294002 were examined. As shown in Figure 6, we observed that there was a significant increase in the number of $\gamma \mathrm{H} 2 \mathrm{AX}$ foci upon LY294002 treatment in TNBC cells. However, HCC1937 cells exhibited higher levels of $\gamma \mathrm{H} 2 \mathrm{AX}$ foci than
MDA-MB-231 cells in response to $20 \mu \mathrm{M}$ of LY294002. Besides, both TNBC cells showed a low level of cytoplasmic staining for RAD51. However, BRCA1-deficient HCC1937 cells were unable to form BRCA1 foci compared to MDAMB-231 cells. Therefore, higher of cytoplasmic BRCA1 and RAD51 expressions were observed in MDA-MB-231 cells.
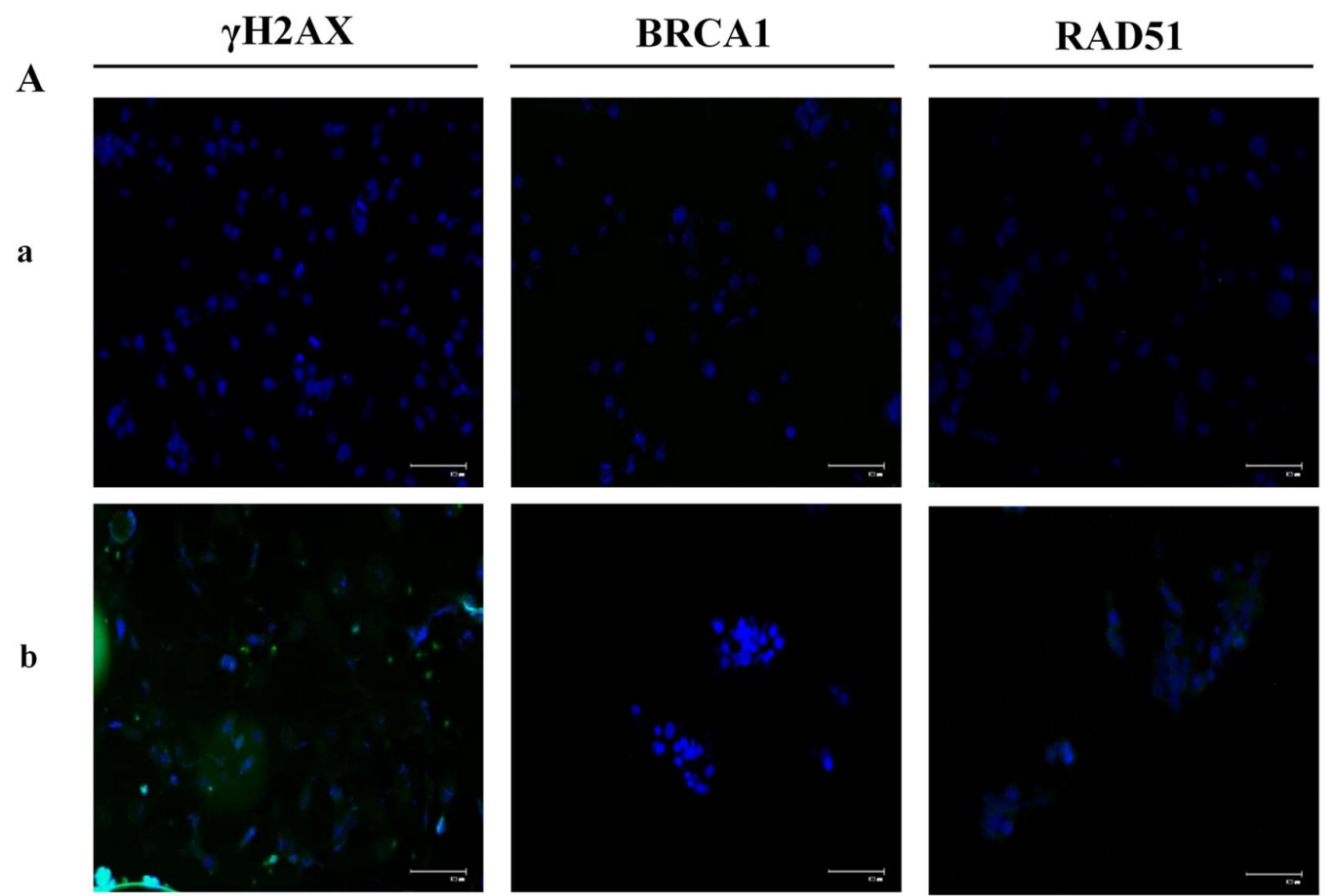

B
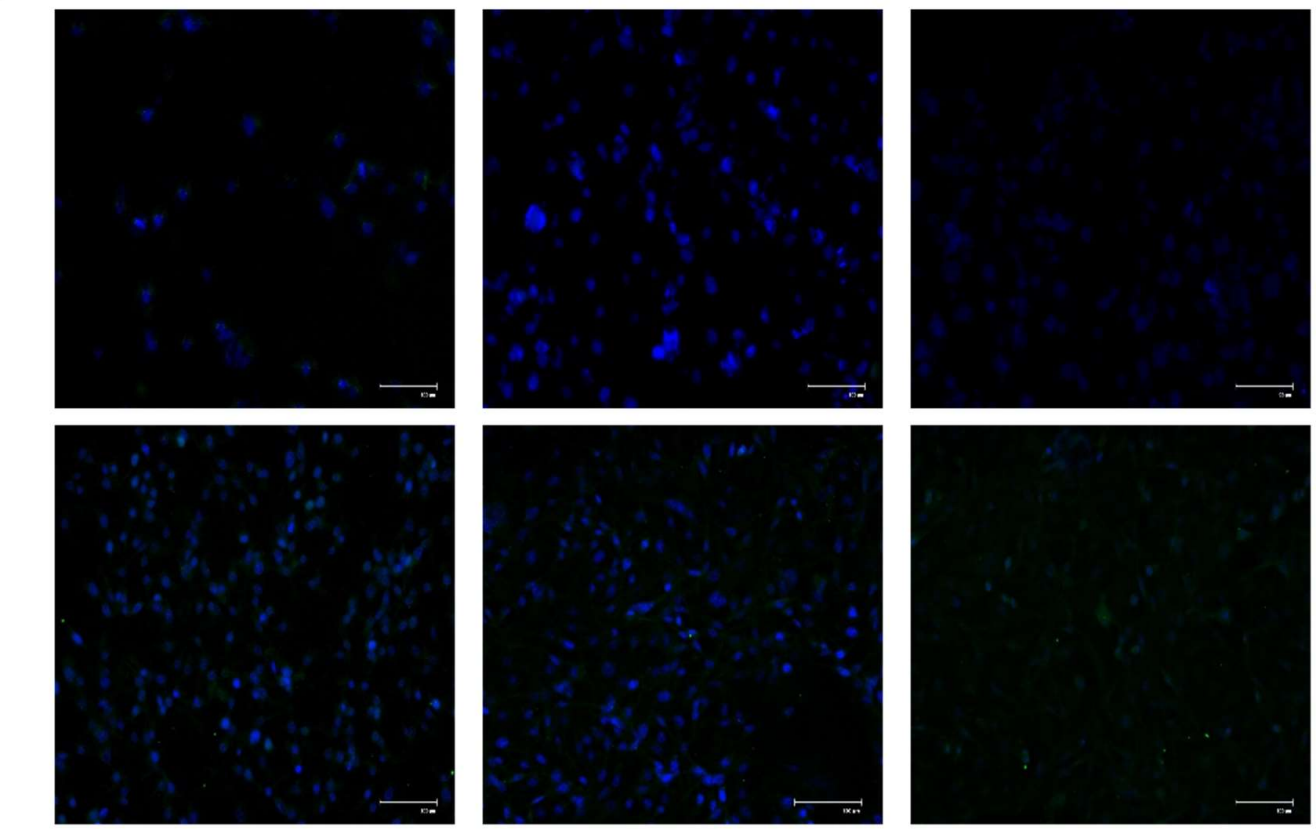

Figure 6. The localization of $\gamma \mathrm{H} 2 \mathrm{AX}$, BRCA1 and RAD51 in (A) HCC1937 and (B) MDA-MB-231 cells in response to LY294002 exposure [(a) control and (b) $20 \mu \mathrm{M}$ of LY294002]. 


\section{DISCUSSION}

Here, the association of PI3K inhibition with HR repair mechanism has been investigated in TNBC. The findings suggest that the suppression of PI3K leads to impair BRCA1 and RAD51 mRNA and protein expression in TNBC cells. PI3K inhibition can result in increased expression of $\gamma-\mathrm{H} 2 \mathrm{AX}$, as a marker of DNA damage, apoptotic cell death and G0/G1 phase arrest. Additionally, LY294002, an inhibitor of PI3K, is more effective in BRCA1deficient TNBC cells. Thus, the therapeutic potential of PI3K inhibitors is closely linked with HR impairment in TNBC.

The overexpression of $\mathrm{PI} 3 \mathrm{~K} / \mathrm{AKT} / \mathrm{mTOR}$ pathway is associated with poor clinical outcomes of patients with breast cancer. Thus, the inhibition of PI3K pathway is a potential therapeutic target for treating breast cancer (16-18). In this context, the efficacy of PI3K/AKT/mTOR pathway inhibitors in the treatment of advanced solid tumors including lung, pancreatic, breast and ovarian cancer etc. have been investigated in preclinical and clinical studies (19-23).

TNBC is a highly aggressive heterogeneous subtype of breast cancer with a higher rates of distant recurrence (1-4). Previous studies have revealed that TNBC patients showed a higher prevalence of PTEN and PI3K mutations and overactivation of mTOR pathway compared to other subtypes of breast cancer (18, 24-26). Thus, panPI3K inhibitors (buparlisib, pictilisib, AR245408, taselisib, and PX-866) and isoform-specific PI3K inhibitors (alpelisib) have been extensively studied in the treatment of breast cancer subtypes $(13,27$, 28). Moreover, alpelisib has been approved by The US Food and Drug Administration (FDA) for the treatment of postmenopausal women and men patients with HR+, HER2-, PIK3CA mutated advanced or metastatic breast cancer.

LY294002, a reversible inhibitor of PI3K as a derivative of quercetin, inhibits certain mammalian PI3Ks including mTOR (mammalian target of rapamycin), DNA-PK (DNA-dependent protein kinase), other protein kinases (CK2 (casein kinase 2) and Pim-1) (29, 30). Previous studies have shown that LY294002 sensitizes cerulenininduced apoptotic cell death, inhibits BCRPmediated drug resistance and increases GSK-3 $\beta$ activity by adenovirus-mediated gene transfer of PTEN in different types of breast cancer cell lines (MCF-7 and MBA-MB468 cells) (31-33). In the current study, LY294002 inhibits the proliferation of TNBC cells irrespective of BRCA1 mutation status and induces apoptotic cell death and cell cycle arrest at G0/G1 phase. However, the inhibition of PI3K is more profound in BRCAI mutant TNBC cell line.

Recent studies have also revealed that $\mathrm{PI} 3 \mathrm{~K} / \mathrm{Akt}$ inhibition is associated with impairment of DNA repair in different types of cancer cells including glioblastoma, endometrial, ovarian and pancreatic cancer (34-37). Park et al. (2017) state that HS-173 PI3K inhibitor enhances radiotherapy by suppressing the DNA damage-repair pathway in pancreatic cancer cell (34). Additionally, studies of Philip et al. (2017) and Wang et al (2016) demonstrate that BKM-120 treatment is effectively blocked RAD51 foci formation and cause downregulation of BRCA in PTEN mutated endometrial cancer cells and PIK3CA mutated ovarian cancer cells, respectively and the dual inhibition of PI3K and PARP by PARP inhibitors (talazoparib and olaparib) may be an effective therapeutic approach for endometrial and ovarian cancer $(35,36)$. Furthermore, Ibrahim et al. (2012) show that PI3K inhibition by BKM-120 induces DNA damage, downregulation of BRCA1/2, and combined inhibition of PI3K and PARP indicates significant antitumor activity in $B R C A$-wild-type TNBC cell lines (MDA-MB-468, MDA-MB-231, HCC70, HCC1143, and BT20) and TNBC patientderived primary tumor xenograft (38). In the present study, the suppression of PI3K by LY94002 is accompanied by downregulation of $B R C A 1$ and $R A D 51$ gene and protein expression and promotes the accumulation of $\gamma \mathrm{H} 2 \mathrm{AX}$ in TNBC. However, treatment with LY294002 leads to considerably reduced the expression levels of $B R C A 1$ and RAD51, but increased the level of $H 2 A F X$ mRNA expression and $\gamma \mathrm{H} 2 \mathrm{AX}$ foci formation and thus, LY294002 causes more apoptotic cell death in BRCA1-deficient TNBC cells. The apoptotic effect of LY294002 is correlated with increased the expression level of $B A X$ and reduced the level of $B C L-2$.

Consequently, these results suggest that a significant link between PI3K inhibition and HR mechanism in TNBC. Thus, PI3K/AKT targeting by PI3K inhibitors may be potential therapeutic implications for TNBC patients with $B R C A$ mutations or HR deficiency. However, further molecular investigations are needed to identify the efficacy of LY294002 in DNA repair mechanisms including HR, non-homologous end-joining (NHEJ), microhomology-mediated end-joining (MMEJ), alternative NHEJ (alt-NHEJ), synthetic lethality, "BRCAness", and the Fanconi anemia signaling network (39).

Additionally, the combination treatment of LY294002 with especially PARP inhibitors and comparison of the effectiveness of LY294002 with 
other PI3K inhibitors in TNBC are further investigated by in vitro and in vivo.

\section{CONFLICT OF INTEREST}

The authors declare that they have no conflict of interest.

\section{REFERENCES}

1. Carey L, Winer E, Viale G, Cameron D, Gianni L. Triple-negative breast cancer: disease entity or title of convenience?. Nat. Rev. Clin. Oncol, 2010; 7(12): 683-692. doi: 10.1038/nrclinonc.2010.154.

2. Anders CK, Carey LA. Biology, metastatic patterns, and treatment of patients with triplenegative breast cancer. Clin Breast Cancer, 2009; 9(Suppl 2): 73-81. doi: 10.3816/CBC.2009.s.008.

3. Bianchini G, Balko JM, Mayer IA, Sanders ME, Gianni L. Triple-negative breast cancer: challenges and opportunities of a heterogeneous disease. Nat. Rev. Clin. Oncol, 2016; 13(11): 674. doi: 10.1038/nrclinonc.2016.66.

4. Guney Eskiler G, Cecener G, Egeli U, Tunca B. Triple negative breast cancer: new therapeutic approaches and BRCA status. Apmis, 2018; 126(5): 371-379. doi: 10.1111/apm.12836.

5. Ratanaphan A. A DNA repair BRCA1 estrogen receptor and targeted therapy in breast cancer. Int. J. Mol. Sci, 2012; 13(11): 14898-14916. doi: 10.3390/ijms131114898.

6. Stoppa-Lyonnet D. The biological effects and clinical implications of BRCA mutations: where do we go from here?. Eur J Hum Genet, 2016; 24(S1): S3. doi: 10.1038/ejhg.2016.93.

7. Hahnen E, Hauke J, Engel C, Neidhardt G, Rhiem $\mathrm{K}$, Schmutzler RK. Germline mutations in triplenegative breast cancer. Breast Care, 2017; 12(1): 15-19. doi: 10.1159/000455999.

8. Chen CC, Feng W, Lim PX, Kass EM, Jasin M. Homology-directed repair and the role of BRCA1, BRCA2, and related proteins in genome integrity and cancer. Annu. Rev. Cancer Biol, 2018; 2: 313336. doi: 10.1146/annurev-cancerbio-030617050502 .

9. Ossovskaya V, Wang Y, Budoff A, Xu Q, Lituev A, Potapova O, Vansant G, Monforte J, Daraselia N. Exploring molecular pathways of triple-negative breast cancer. Genes \& cancer, 2011; 2(9): 870879. doi: 10.1177/1947601911432496.

10. Belli C, Duso BA, Ferraro E, Curigliano G. Homologous recombination deficiency in triple negative breast cancer. The Breast, 2019; 45: 1521. doi:10.1016/j.breast.2019.02.007.

11. Martini M, De Santis MC, Braccini L, Gulluni F, Hirsch E. PI3K/AKT signaling pathway and cancer: an updated review. Ann. Med, 2014; 46(6): 372-383. doi: 10.3109/07853890.2014.912836.
12. Mayer IA, Arteaga CL. The PI3K/AKT pathway as a target for cancer treatment. Ann. Med, 2016; 67: 11-28. doi: 10.1146/annurev-med-062913-051343.

13. Qin H, Liu L, Sun S, Zhang D, Sheng J, Li B, Yang W. The impact of PI3K inhibitors on breast cancer cell and its tumor microenvironment. PeerJ, 2018; 6: e5092. doi: 10.7717/peerj.5092.

14. Davis NM, Sokolosky M, Stadelman K, Abrams SL, Libra M, Candido S, Nicoletti F, Polesel J, Maestro R, D'Assoro A, Drobot L, Rakus D, Gizak A, Laidler P, Dulińska-Litewka J, Basecke J, Mijatovic S, Maksimovic-Ivanic D, Montalto G, Cervello M, Fitzgerald TL, Demidenko Z, Martelli AM, Cocco L, Steelman LS, McCubrey JA. Deregulation of the EGFR/PI3K/PTEN/Akt/mTORC1 pathway in breast cancer: possibilities for therapeutic intervention. Oncotarget, 2014; 5(13): 4603. doi: 10.18632/oncotarget.2209.

15. Krajewska M, Fehrmann RS, de Vries EG, van Vugt MA. Regulators of homologous recombination repair as novel targets for cancer treatment. Frontiers in genetics, 2015; 6: 96. doi: 10.3389/fgene.2015.0009.

16. Guimarães IS, Tessarollo NG, Lyra-Júnior PCM, dos Santos DZ, Zampier RC, de Oliveira LFRL, Siqueira KV, Silva IV, Rangel LBA. Targeting the $\mathrm{PI} 3 \mathrm{~K} / \mathrm{AKT} / \mathrm{mTOR}$ Pathway in Cancer Cells in Updates on Cancer Treatment (Edited by Letícia Rangel and Ian Victor Silva). 2015, doi: $10.5772 / 58657$.

17. Costa RL, Han HS, Gradishar WJ. Targeting the $\mathrm{PI} 3 \mathrm{~K} / \mathrm{AKT} / \mathrm{mTOR}$ pathway in triple-negative breast cancer: A review. Breast Cancer Res Treat, 2018; 169(3): 397-406. doi: 10.1007/s10549-0184697-y.

18. Massihnia D, Galvano A, Fanale D, Perez A, Castiglia M, Incorvaia L, Listì A, Rizzo S, Cicero G, Bazan V, Castorina S, Russo A. Triple negative breast cancer: shedding light onto the role of pi3k/akt/mtor pathway. Oncotarget, 2016; 7(37): 60712. doi: 10.18632/oncotarget.10858.

19. Zhao HF, Wang J, Shao W, Wu CP, Chen ZP, To SST, Li WP. Recent advances in the use of PI3K inhibitors for glioblastoma multiforme: current preclinical and clinical development. Mol cancer, 2017; 16(1): 100. doi: 10.1186/s12943-017-06703.

20. Zhao W, Qiu Y, Kong D. Class I phosphatidylinositol 3-kinase inhibitors for cancer therapy. Acta Pharm Sin B, 2017; 7(1): 27-37. doi: 10.1016/j.apsb.2016.07.006.

21. Janku F. Phosphoinositide 3-kinase (PI3K) pathway inhibitors in solid tumors: From laboratory to patients. Cancer Treat. Rev, 2017; 59: 93-101. doi: 10.1016/j.ctrv.2017.07.005.

22. Raphael J, Desautels D, Pritchard KI, Petkova E, Shah PS. Phosphoinositide 3-kinase inhibitors in advanced breast cancer: A systematic review and meta-analysis. Eur J Cancer, 2018; 91: 38-46. doi: 10.1016/j.ejca.2017.12.010. 
23. Akinleye A, Avvaru P, Furqan M, Song Y, Liu D. Phosphatidylinositol 3-kinase (PI3K) inhibitors as cancer therapeutics. J Hematol Oncol, 2013; 6(1): 88 .

24. Garrido-Castro AC, Lin NU, Polyak K. Insights into molecular classifications of triple-negative breast cancer: improving patient selection for treatment. Cancer Discov, 2019; 9(2): 176-198. doi: 10.1158/2159-8290.CD-18-1177.

25. Baselga J. Targeting the phosphoinositide-3 (PI3) kinase pathway in breast cancer. The oncologist, 2011; 16(Supplement 1): 12-19. doi: 10.1634/theoncologist.2011-S1-12.

26. Cossu-Rocca P, Orrù S, Muroni MR, Sanges F, Sotgiu G, Ena S, Pira G, Murgia L, Manca A, Uras MG, Sarobba MG, Urru S, De Miglio MR. Analysis of PIK3CA mutations and activation pathways in triple negative breast cancer. PloS one, 2015; 10(11): e0141763. doi: 10.1371/journal.pone.0141763.

27. Yang J, Nie J, Ma X, Wei Y, Peng Y, Wei X. Targeting PI3K in cancer: mechanisms and advances in clinical trials. Mol Cancer, 2019; 18(1): 26. doi: 10.1186/s12943-019-0954-x.

28. Dienstmann R, Rodon J, Serra V, Tabernero J. Picking the point of inhibition: a comparative review of $\mathrm{PI} 3 \mathrm{~K} / \mathrm{AKT} / \mathrm{mTOR}$ pathway inhibitors. Mol. Cancer Ther , 2014; 13(5): 1021-1031. doi: 10.1158/1535-7163.MCT-13-0639.

29. Gharbi SI, Zvelebil MJ, Shuttleworth SJ, Hancox T, Saghir N, Timms JF, Waterfield MD. Exploring the specificity of the PI3K family inhibitor LY294002. Biochem J, 2007; 404(1): 15-21. doi:10.1042/BJ20061489

30. Liang K, Jin W, Knuefermann C, Schmidt M, Mills GB, Ang KK, Milas L, Fan Z.Targeting the phosphatidylinositol 3-kinase/Akt pathway for enhancing breast cancer cells to radiotherapy1. Mol Cancer Ther, 2003; 2(4): 353-360.

31. Liu X, Shi Y, Giranda VL, Luo Y. Inhibition of the phosphatidylinositol 3-kinase/Akt pathway sensitizes MDA-MB468 human breast cancer cells to cerulenin-induced apoptosis. Mol. Cancer Ther, 2006; 5(3): 494-501. doi: 10.1158/15357163.MCT-05-0049.

32. Imai Y, Yoshimori M, Fukuda K, Yamagishi H, Ueda Y. The PI3K/Akt inhibitor LY294002 reverses BCRP-mediated drug resistance without affecting BCRP translocation. Oncol Rep, 2012; 27(6): 1703-1709. doi: 10.3892/or.2012.1724.

33. Ren Y, Zhou X, Qi Y, Li G, Mei M, Yao Z. PTEN activation sensitizes breast cancer to PI3-kinase inhibitor through the $\beta$-catenin signaling pathway. Oncol Rep, 2012; 28(3): 943-948. doi: 10.3892/or.2012.1856.

34. Park JH, Jung KH, Kim SJ, Fang Z, Yan HH, Son MK, Kim J, Kang YW, Lee JE, Han B, Lim JH, Hong SS. Radiosensitization of the PI3K inhibitor HS-173 through reduction of DNA damage repair in pancreatic cancer. Oncotarget, 2017; 8(68): 112893. doi: 10.18632/oncotarget.22850.

35. Philip CA, Laskov I, Beauchamp MC, Marques M, Amin O, Bitharas J, Kessous R, Kogan L, Baloch T, Gotlieb WH, Yasmeen A. Inhibition of PI3KAKT-mTOR pathway sensitizes endometrial cancer cell lines to PARP inhibitors. BMC cancer, 2017; 17(1): 638. doi: 10.1186/s12885-017-36390 .

36. Wang D, Wang M, Jiang N, Zhang Y, Bian X, Wang X, Roberts TM, Zhao JJ, Liu P, Cheng H. Effective use of PI3K inhibitor BKM120 and PARP inhibitor Olaparib to treat PIK3CA mutant ovarian cancer. Oncotarget, 2016; 7(11): 13153. doi: 10.18632/oncotarget.7549.

37. Maity A, Jiang Z, Fernandes A, Gupta AK, Kao GD. Inhibition of PI3K/Akt Signaling Impairs DNA Repair in Glioblastoma Cells Following Ionizing Radiation. Int J Radiat Oncol Biol Phys, 2007; 69(3): S591. doi: 10.1074/jbc.M703042200.

38. Ibrahim YH, García-García C, Serra V, He L, Torres-Lockhart K, Prat A, Anton P, Cozar P, Guzmán M, Grueso J, Rodríguez O, Calvo MT, Aura C, Díez O, Rubio IT, Pérez J, Rodón J, Cortés J, Ellisen LW, Scaltriti M, Baselga J. PI3K inhibition impairs BRCA1/2 expression and sensitizes BRCA-proficient triple-negative breast cancer to PARP inhibition. Cancer Discov, 2012; 2(11): 1036-1047. doi: 10.1158/2159-8290.

39. Boussios S, Karathanasi A, Cooke D, Neille C, Sadauskaite A, Moschetta M, ZakynthinakisKyriakou N, Pavlidis, N. PARP inhibitors in ovarian cancer: the route to "Ithaca". Diagnostics, 2019; 9(2): 55. doi: 10.3390/diagnostics9020055 
Table 1. Comparison of the percentage of cell viability after treatment with the different concentration of LY294002 in each cell type for $24 \mathrm{~h}$ and $48 \mathrm{~h}$.

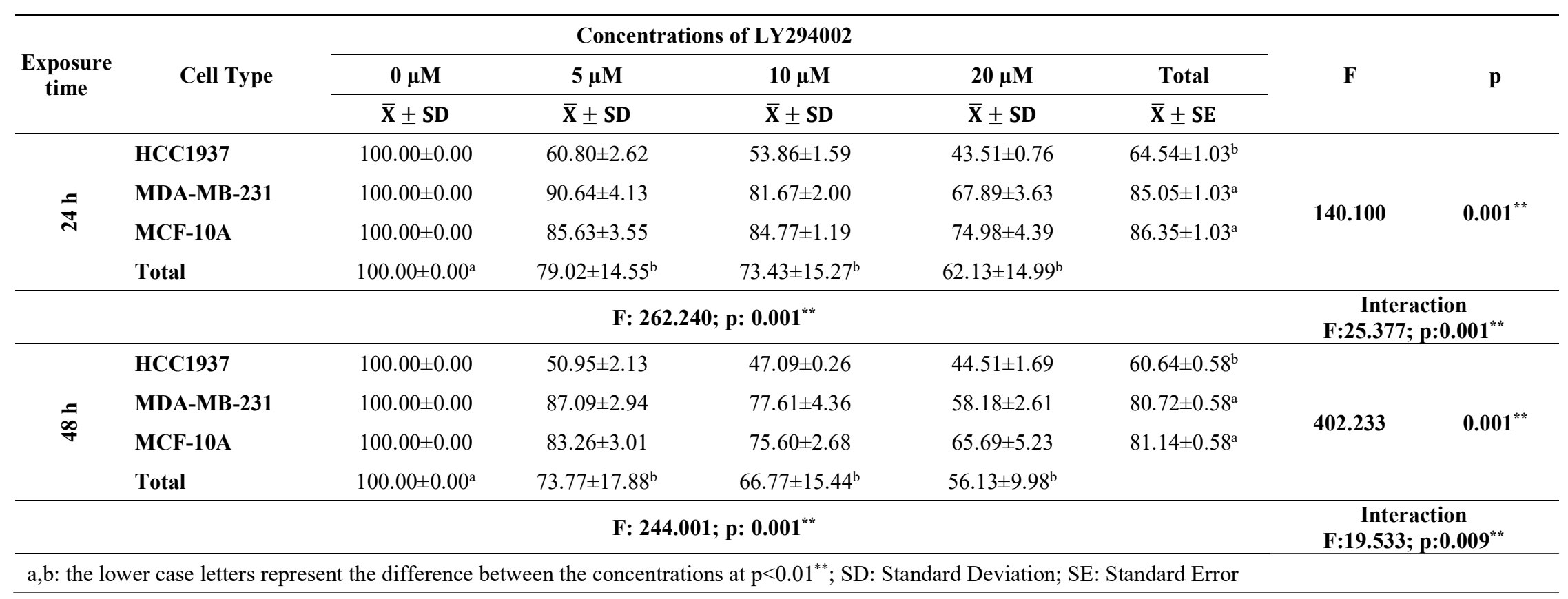


A

(a)

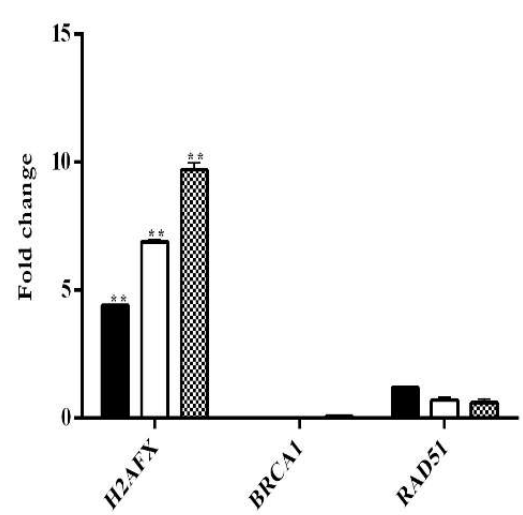

(b)

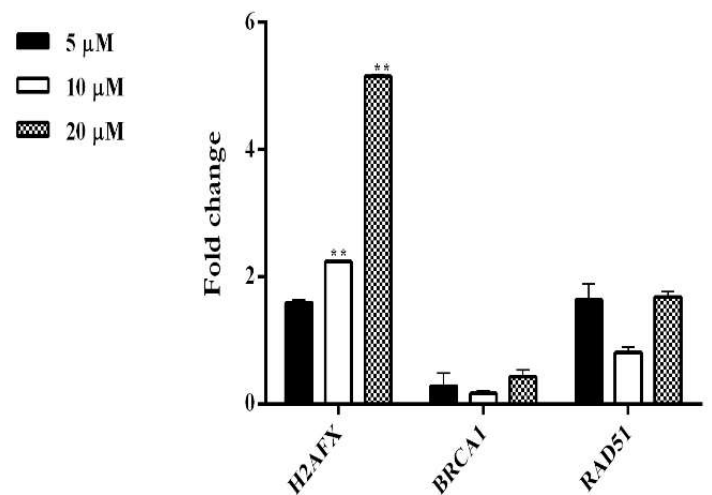

(c)

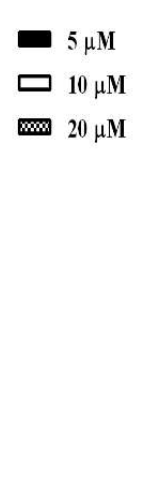

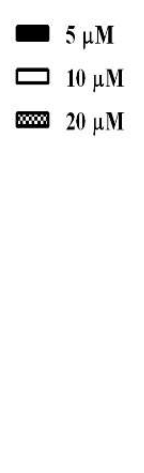

B
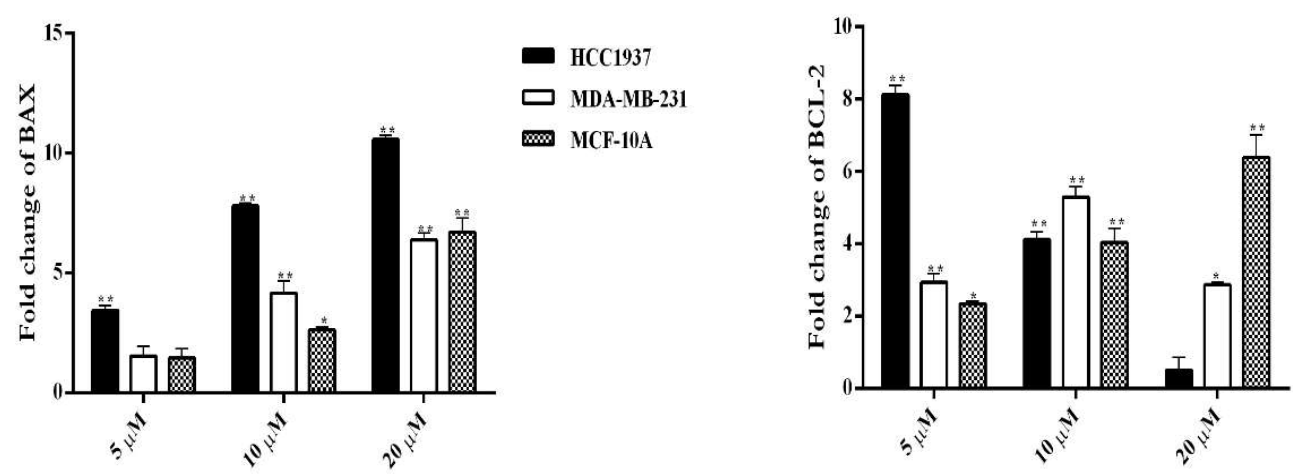

-

$$
\square \text { MDA-MB-231 }
$$

MCF-10A
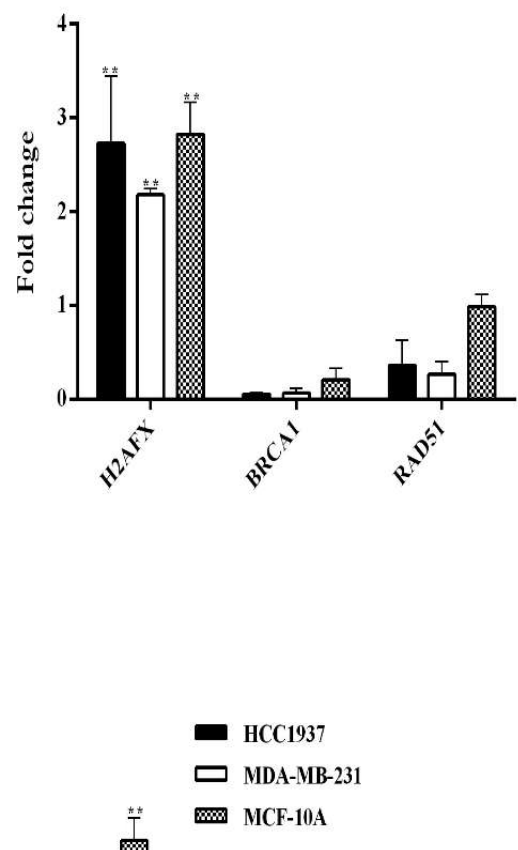

Figure 5. (A) RT-PCR analysis results for $H 2 A F X, B R C A 1$ and $R A D 51$ expression level in (a) HCC1937, (b) MDA-MB-231 and (c) MCF-10A cells. (B) Comparison of $B A X$ and $B C L-2$ expression in TNBC and control cells $\left(\mathrm{p}<0.05^{*}, \mathrm{p}<0.01^{* *}\right)$. 
